\title{
Force analysis of linear induction motor for magnetic levitation system
}

\section{Citation for published version (APA):}

Kuijpers, A. A., Nemlioglu, C., Sahin, F., Verdel, A. J. D., Compter, J. C., \& Lomonova, E. (2010). Force analysis of linear induction motor for magnetic levitation system. In Proceedings of the 2010 14th International Power Electronics and Motion Control Conference (EPE/PEMC), 6-8 September 2010, Ohrid, Republic of Macedonia (pp. S3-17/20). Institute of Electrical and Electronics Engineers.

https://doi.org/10.1109/EPEPEMC.2010.5606578

DOI:

10.1109/EPEPEMC.2010.5606578

Document status and date:

Published: 01/01/2010

\section{Document Version:}

Publisher's PDF, also known as Version of Record (includes final page, issue and volume numbers)

\section{Please check the document version of this publication:}

- A submitted manuscript is the version of the article upon submission and before peer-review. There can be important differences between the submitted version and the official published version of record. People interested in the research are advised to contact the author for the final version of the publication, or visit the $\mathrm{DOI}$ to the publisher's website.

- The final author version and the galley proof are versions of the publication after peer review.

- The final published version features the final layout of the paper including the volume, issue and page numbers.

Link to publication

\section{General rights}

Copyright and moral rights for the publications made accessible in the public portal are retained by the authors and/or other copyright owners and it is a condition of accessing publications that users recognise and abide by the legal requirements associated with these rights.

- Users may download and print one copy of any publication from the public portal for the purpose of private study or research.

- You may not further distribute the material or use it for any profit-making activity or commercial gain

- You may freely distribute the URL identifying the publication in the public portal.

If the publication is distributed under the terms of Article 25fa of the Dutch Copyright Act, indicated by the "Taverne" license above, please follow below link for the End User Agreement:

www.tue.nl/taverne

Take down policy

If you believe that this document breaches copyright please contact us at:

openaccess@tue.nl

providing details and we will investigate your claim. 


\title{
Force Analysis of Linear Induction Motor for Magnetic Levitation System
}

\author{
A.A. Kuijpers", C. Nemlioglu*, F. Sahin ${ }^{*}$, A.Verdel ${ }^{\dagger}$, J.C. Compter ${ }^{\dagger}$, E.A. Lomonova ${ }^{\dagger}$ \\ * Philips Applied Technologies/Mechatronics, Eindhoven, The Netherlands, e-mail: Toon.Kuijpers@philips.com \\ ${ }^{\dagger}$ Eindhoven University of Technology/EPE, Eindhoven, The Netherlands, e-mail: E.Lomonova@tue.nl
}

\begin{abstract}
This paper presents the analyses of thrust and normal forces of linear induction motor (LIM) segments which are implemented in a rotating ring system. To obtain magnetic levitation in a cost effective and sustainable way, decoupled control of thrust and normal forces is required. This study includes the design of a static test setup from which the measurement results are compared and verified with the derived analytical methods and finite element simulations. The comparison shows significant correlation of the thrust and normal forces as function of the slip frequency .
\end{abstract}

Keywords-LIM, Decoupled Control, Magnetic Levitation, Magnetic Bearing, Longitudinal End Effect, Transverse Edge Effect, Saturation, Skin Effect.

\section{INTRODUCTION}

Magnetic levitation and bearing systems implementing permanent magnets (PM) are widely accepted e.g. [1], [2]. Here, we would like to focus on a topology which does not contain permanent magnets because of the advantages in terms of cost reduction, ease of assembly due to the absence of magnetic attraction forces and sustainability due to the avoidance of rare-earth materials.

This paper presents a feasibility study of a novel magnetic levitation system through the use of Single-sided Linear Induction Motor (SLIM) segments implemented in a rotating ring system. Levitation and rotation of this ring system is realized by the SLIM segments and requires a simultaneous, decoupled control of the generated thrust and normal forces.

Available publications about LIMs are very diverse and mostly written for a particular LIM with a specific operation. This shows the importance of an analytical model that corresponds with the SLIM under investigation, in our case the three phase double-layer secondary flat SLIM. A good realistic analytical model gives a clear derivation of thrust and normal forces and takes into account the following four effects: longitudinal end effect, transverse edge effect, saturation and skin effects.

Publications found about vector controlled LIMs [3]-[7] are not sufficient enough to build an analytical model from, none of these five papers includes all pre-described four parasitic effects.

The next set of papers [8]-[11] discusses various ways of decoupling the thrust and normal forces simultaneously. A control method of thrust and normal forces using the combined power source, which has a low frequency and a high frequency component, is proposed in [8]. The low frequency component is used to control thrust force and supports the weight of the system, and the high frequency component is used to control the normal force. Another method [9] shows how the slip frequency can be determined uniquely from dividing the thrust force $F_{t}$ by the normal force $F_{n}$ according to $F_{t} / F_{n}=$ function $\left(f_{\text {slip }}\right)$. From the unique slip frequency, the reference thrust force and the air gap length, the primary current and the power supply frequency of the LIM can be derived.

Yamamura [12] extensively discusses the double-sided secondary flat LIM with longitudinal end effects. The difference between the single-layer and double-layer secondary lies in the secondary back iron. Because Yamamura's model does not consist of a secondary back iron no saturation is derived. Also the transverse edge effect is not implemented in his model.

Two analytical models have been chosen to be implemented and executed for the performance calculation of the SLIM. The first one is based on the theory of Gieras [13]-[14], the other one on the theory of Boldea \& Nasar [15]-[16]. Both theoretical approaches provide solutions for the longitudinal end effects, transverse edge effects, skin effects and saturation. Both theories are applicable, because they are developed for the same double-layer secondary flat SLIM.

The specifications and characteristics of the SLIM under investigation are described in Section II. The two analytical models, followed by a numerical model of the SLIM are respectively discussed in Sections III and IV. Section V describes the measurement setup, and Section VI shows the results of the measurements and validates them with the results of the analytical and numerical models. Finally, Section VII gives the overall conclusions and recommendations.

\section{SPECIFICATIONS OF THE SLIM}

The arc-shaped SLIM consists of a fixed primary and a moving secondary. Fig. 1 shows the arc-shaped primary without windings. The primary teeth and back iron are made of $0.35 \mathrm{~mm}$ iron silicon laminated material M235$35 \mathrm{~A}$, and has a pack of 200 laminations to prevent major influence of eddy currents in the primary. Increasing the number of poles will improve the force capability, however, it will also increase the manufacturing complexity and costs of a SLIM segment. Among these design criteria a trade-off has been made; the SLIM is constructed with 4 pole pairs. 


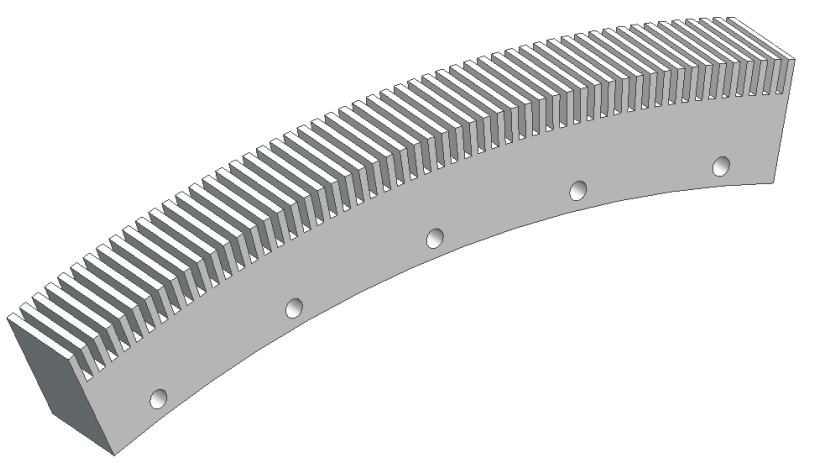

Fig. 1. Arc-shaped primary in 3D drawn model shown without the windings

The primary windings are shown in Fig. 2. One should notice the double layer of windings in Fig. 2(a) which improves the magnetic flux distribution and reduces the resistance and leakage reactance significantly. Also the half end slots at both ends of the primary can be seen, it is $5 / 6$ short pitched to eliminate the $5^{\text {th }}$ and $7^{\text {th }}$ order harmonics of the induced magnetic flux density, which is a major disturbance [17].

The total width of the primary of $120 \mathrm{~mm}$ is given by summing up the primary core width Lprim of $70 \mathrm{~mm}$ and the width of the end windings of $50 \mathrm{~mm}$.

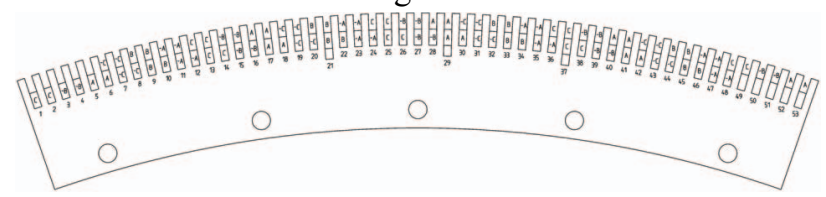

(a)

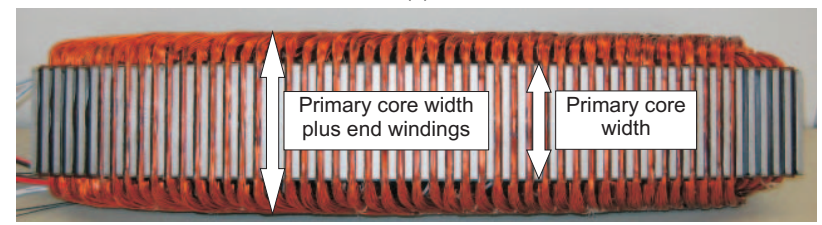

(b)

Fig. 2. (a) Windings layout of primary in setup with double layer windings, half filled end slots and 5/6 short pitched windings and (b) the primary core including end windings.

The secondary of the SLIM consists of a nonferromagnetic high conductive Aluminum T633/80 (Also known as AlSilMgMn) layer backed up with a ferromagnetic steel (also known as 11SMn28) core. To produce a high magnetic flux density from a certain amount of current it is important to keep the height of the air gap $\mathrm{g}$ as small as possible, therefore it is set at $1 \mathrm{~mm}$.

All the parameters and dimensions of the primary and the secondary of the SLIM are summarized in [18]. The total length of the primary equals a length according to $\left[\tau \cdot(2 \mathrm{p}+5 / 6)+\mathrm{w}_{\mathrm{t}}\right]$, with pole pitch $\tau$, number of pole pairs $p$ and $w_{t}$ the width of teeth. Fig. 3(a) illustrates the SLIM parameters.

\section{ANALYTICAL MODELS}

Two analytical models based on theoretical approaches of Gieras [13], [14] and Boldea \& Nasar [15], [16] have been implemented in Mathcad software and contain the derivation of thrust and normal forces and the longitudinal end effect, the transverse edge effect, skin effect and magnetic saturation.
For a complete derivation of the formulas one is referred to [18]. Fig. 3 shows two schematic drawings with parameters of the SLIM which are convenient during the derivation of the force equations. The upcoming equations (2-5) are the same for both analytical models, the equivalent air gap $\mathrm{g}_{\mathrm{c}}$ is given by:

$$
\begin{aligned}
g_{c} & =g \frac{k_{C}(g+d) g+d^{2}-g d}{g^{2}+d^{2}}, \\
k_{C} & =\frac{t_{1}}{t_{1}-\gamma g_{t}}, \\
\gamma & =\frac{4}{\pi}\left\{\frac{w_{\text {slot }}}{2 g_{t}} \arctan \frac{w_{\text {slot }}}{2 g_{t}}-\ln \sqrt{1+\left(\frac{w_{\text {slot }}}{2 g_{t}}\right)^{2}}\right\}, \\
g_{t} & =g+d,
\end{aligned}
$$

with $\mathrm{k}_{\mathrm{C}}$-the Carter coefficient, $\mathrm{t}_{1}$-the primary slot pitch, $\mathrm{g}_{\mathrm{t}}$-the total resultant air gap and $\gamma$-empirical coefficient.

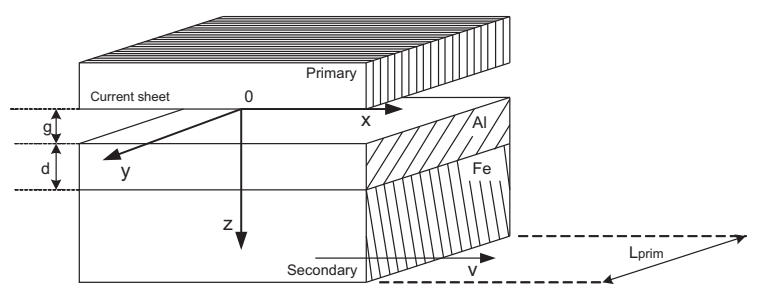

(a)

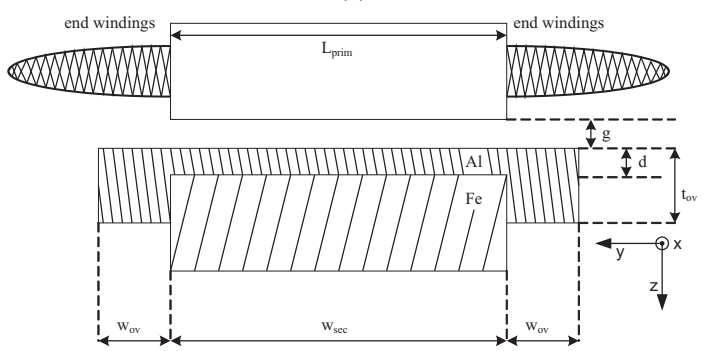

(b)

Fig. 3. SLIM parameters given by (a) 3D schematic drawing and (b) 2D schematic cross-section

\section{A. Gieras Model}

The approach of Gieras is based on a solution of the two-dimensional (2D) electromagnetic field distribution. Successively, the longitudinal End effect, the transverse edge effect, the saturation and the impedance are derived. With the help of Fig 4, the thrust force $F_{t}$ is derived, from the primary and secondary current with the longitudinal end effect factor according to:

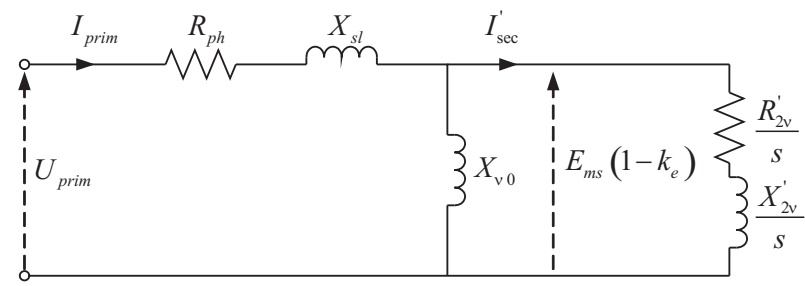

Fig. 4 Per phase equivalent circuit of the SLIM according to Gieras [13]

$$
F_{t}=\frac{m_{p h}\left(I_{s e c}^{\prime}\right)^{2} R_{2 \nu}^{\prime}}{s v_{s}} .
$$

with $\mathrm{I}_{\mathrm{sec}}$, a function of $\mathrm{E}_{\mathrm{ms}}$ and primary current $\mathrm{I}_{\text {prim }}$ (Fig. 4). 
The normal force $F_{n}$ is the subtraction of the attractive force $F_{n a}$ and the repulsive eddy current reaction force $F_{n r}$ given by:

$$
F_{n}=F_{n a}-F_{n r} .
$$

The repulsive eddy current reaction force $F_{n r}$ increases simultaneously with an increase in slip frequency, which means that the total net normal force $\mathrm{F}_{\mathrm{n}}$ decreases. Finally, the attractive and repulsive forces are:

$$
\begin{aligned}
F_{n a} & =\frac{B_{z g}^{2}}{4 \mu_{0}} A, \\
F_{n r} & =F_{t} \frac{B_{x g}}{B_{z g}},
\end{aligned}
$$

with $\mathrm{B}_{\mathrm{xg}}$ - and $\mathrm{B}_{\mathrm{zg}}$-the air gap magnetic flux density in the $\mathrm{x}$ - and $\mathrm{z}$-direction and $\mathrm{A}$ the active surface of the primary core.

\section{B. Boldea \& Nasar Model}

This approach neglects the core losses and at rated frequency the skin effect is small, therefore $X_{2}{ }^{\prime} \approx 0$. The mechanical power and the secondary loss are represented by resistances $R_{m}{ }^{\prime}$ and $R_{2}$ ' in Fig. 5 to take into account the longitudinal end effect. The quasi-one-dimensional theory includes the transverse edge effect, skin effect and secondary saturation by means of appropriate coefficients, implemented by equivalent secondary conductivity $\sigma_{\mathrm{e}}$ and equivalent gap $\mathrm{g}_{\mathrm{e}}$

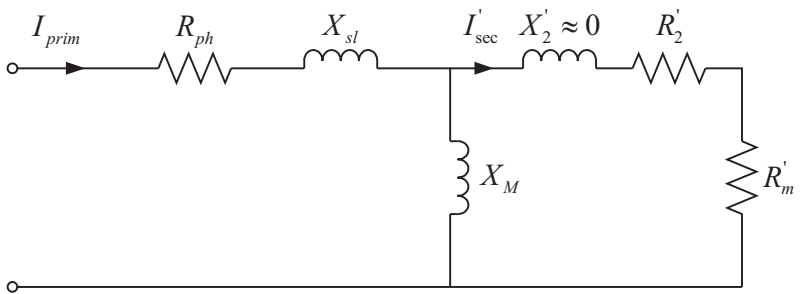

Fig. 5. Per phase equivalent circuit of the SLIM according to Boldea \& Nasar [15].

This model only takes into account the fundamental space harmonic, so the primary current sheet of becomes:

$$
J_{m}=\frac{m_{p h} \sqrt{2} I_{\text {prim }} N k_{w}}{p \tau} .
$$

The derivation of the longitudinal end effect, the transverse edge effect, the saturation and the impedance [18] leads to the calculation of the thrust force $F_{t}$ and normal force $\mathrm{F}_{\mathrm{n}}$, according to:

$$
F_{t}=\mu_{0} a_{e} J_{m} \frac{1}{k} R e\left[A_{2}^{*} \frac{\left(\exp \left[\left(\gamma_{2}^{*}-j\right) k 2 p \tau\right]-1\right)}{\gamma_{2}^{*}-j}+H_{n}^{*} k 2 p \tau\right]
$$

$$
F_{n}=\frac{W_{m}}{g_{e}}+a_{e} \mu_{0} g_{e} R e\left[\int_{0}^{2 p \tau} J_{m} \exp [j k x] \frac{\partial H_{r}}{\partial x} d x\right]
$$

where $a_{e}$ is the equivalent width, $A_{2}$ - the air gap magnetic vector potential, $\gamma_{2}$-the air gap field propagation constant, $\mathrm{H}_{\mathrm{n}}$ - the conventional air gap field, $\mathrm{H}_{\mathrm{r}}$-the air gap reaction field, $\mathrm{J}_{\mathrm{m}}$ the current sheet density and, * - the complex conjugate value. A complete comparison between analytical models and FEM model is given in [18].

\section{NUMERICAL MODEL}

Numerical models have been made with finite element (FE) program OPERA-2D using three modules, namely the Static Field, AC eddy current and the transient eddy current solvers. The specifications, i.e. the dimensions and parameters of the system given in [18], are implemented in OPERA-2D via the pre-processor. Fig. 6 shows the overall drawing of the SLIM, Fig. 6 (b) and (c) respectively illustrate the SLIM zoomed in without and with mesh. As a consequence of the 2D-FEM analysis, the width of the SLIM is considered infinite and the primary width $\mathrm{L}_{\text {prim }}$ is assumed equal to the secondary width $\mathrm{w}_{\text {sec }}$. Consequently, the transverse edge effect is excluded from the resulting final solution.

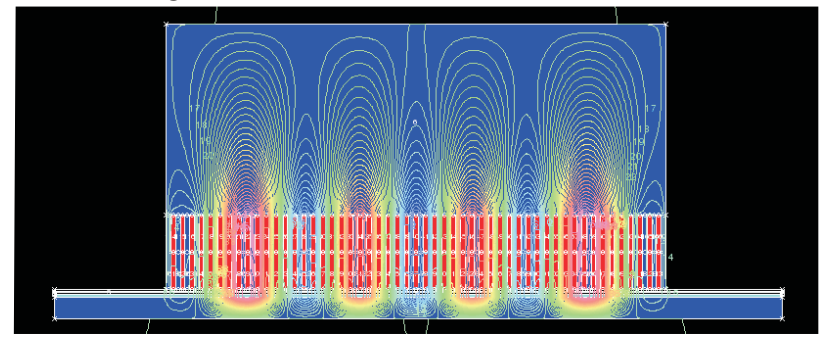

(a)

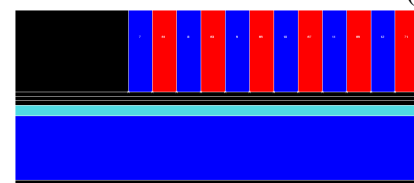

(b)

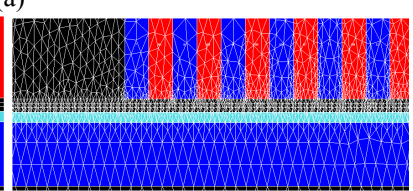

(c)
Fig. 6. (a) The overall SLIM model, (b) the SLIM zoomed in air gap and (c) the SLIM zoomed in on air gap with mesh.

\section{MEASUREMENT SetuP}

A static test setup in Fig. 7 has been designed and constructed to acquire measurement data from the SLIM. The double layer secondary ring has a length of $1000 \mathrm{~mm}$ and a radius of $801 \mathrm{~mm}$. The radius of the ring has been assembled by a steamroller, which introduces inaccuracies in the radius. As a result, at both ends of the SLIM the air gap is significantly bigger than in the middle and does not match the preferably uniform height of $1.0 \mathrm{~mm}$. The average air gap height is determined with backward-fitting of the air gap, using the analytical, equations (5) - (10), and the numerical models.

The primary is attached to a 4 DoF piezoelectric force sensor, i.e. the Kistler 9272, which measures the torque $T_{z}$ and the three orthogonal components of force $F_{x}, F_{y}$ and $\mathrm{F}_{\mathrm{z}}$. The Kistler 9272 sensor has a high natural frequency $(>4 \mathrm{KHz})$ enabling high resolution Force measurements.

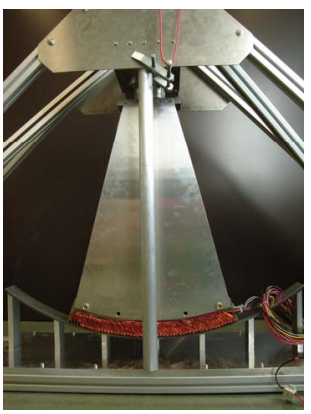

(a)

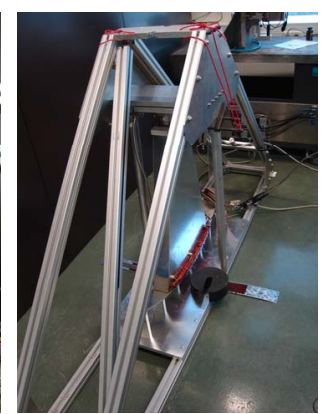

(b)
Fig. 7. The static test setup shown in: (a) front view and (b) side view 
Fig. 8 shows a schematic block diagram of the measurement setup. RMS current values from 4.15 till $6.8 \mathrm{~A}$ with frequency range from $0-200 \mathrm{~Hz}$ are applied with the AC Power Amplifier (ACPA).

The output voltage of the Kistler 5019 charge amplifier is connected with the DSPT SigLab 20-42, a four channel dynamic signal analyzer (16-bit resolution), operated with SigLab and MATLAB software.

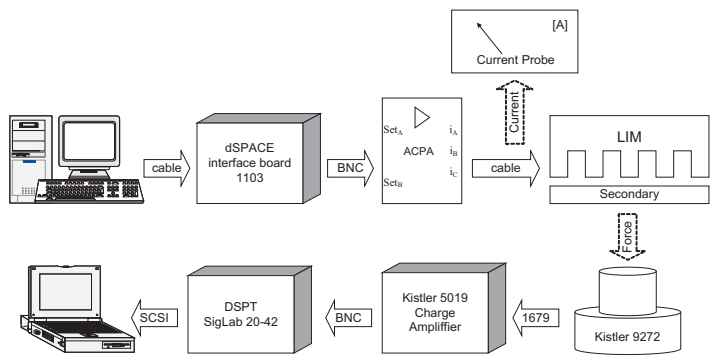

Fig. 8. Measurement setup illustrated in block diagram.

\section{RESULTS}

The numerical results of FEM in Fig. 9 are lower than the measured ones, mainly because of the earlier given implicit assumptions by the 2D-analysis. As a consequence the transverse edge effect is excluded and this lowers the conductivity $\sigma_{\mathrm{Al}}$. Other effects that contribute to the deviation between the measured and the 2D-FEM results are [18] e.g. deviations in the construction, non-uniform air-gap, drift of the force sensor, etc. The analytical and 2D-FEM models are a good approximation and useful tools for this feasibility analysis.

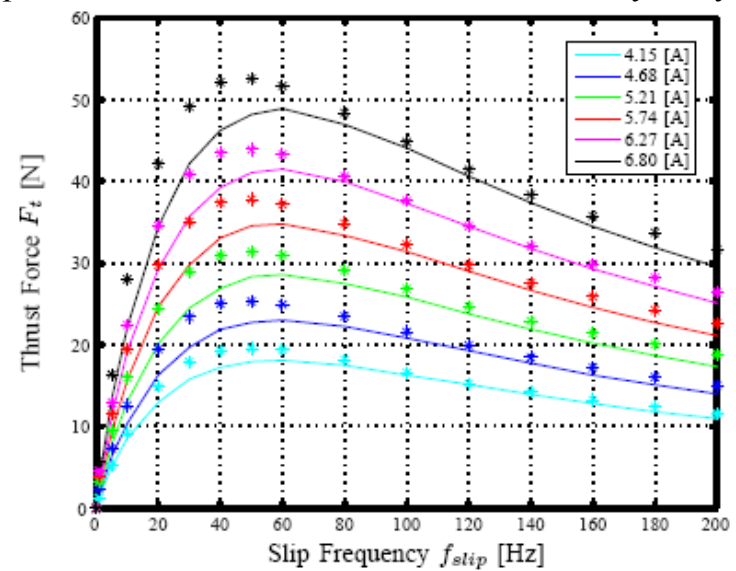

(a)

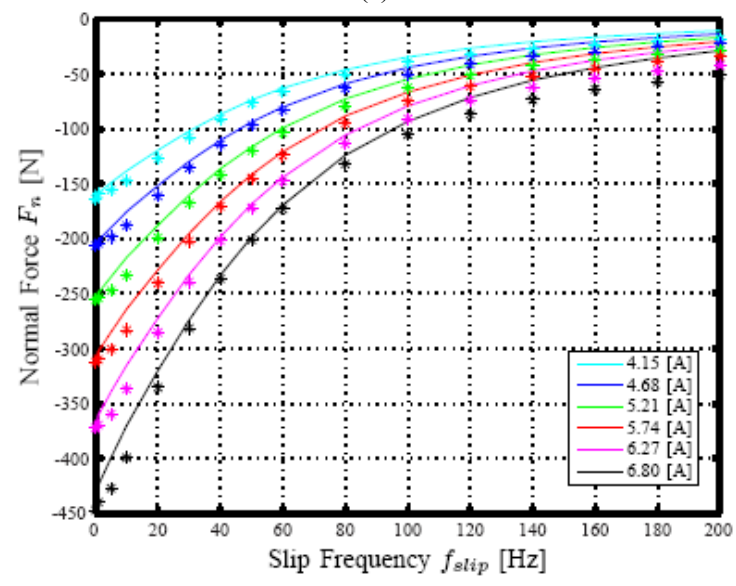

(b)

Fig. 9. FEM (-) and measured (*) results of (a) $F_{t}$ and (b) $F_{n}$

\section{CONCLUSIONS \& RECOMMENDATIONS}

This paper has shown various analyzing methods for the thrust and normal forces for a novel magnetically levitated system using SLIM segments in a rotating ring system. A test-setup has been constructed and measured and compared and validated with analytical and numerical results. Model comparison shows significant correlation of the thrust and normal forces as function of the slip frequency. The analytical models and 2D-FEM model are useful tools in approximating and predicting the measured results for this novel magnetic levitation system.

\section{REFERENCES}

[1] J.C. Compter, P.C.M. Frissen, "Displacement Device", Filing date: 1-05-1001, World Intellectual Property Organization, WO01/91204.

[2] J. de Boeij, E.A. Lomonova, A.J.A. Vandenput, Optimization of contactless planar actuator with manipulator., IEEE Transactions on Magnetics, 44(6), 1118-1121, 2008

[3] A.K.Rathore and S.N.Mahendra, "Simulation of secondary flux oriented control of linear induction motor considering attraction force \& transverse edge effect," 9th IEEE International Power Electronics Congress, pp. 158-163, 17-22, 2004.

[4] J.H.Sung and K.Nam, "A new approach to vector control for a linear induction motor considering end effects," IEEE Industry Applications Conference, Thirty-Fourth IAS Annual Meeting, vol. 4, pp. 2284-2289, 3-7, 1999.

[5] G.Kang and K.Nam, "Field-oriented control scheme for linear induction motor with the end effect," IEE Proc. Electr. Power Appl., vol. 152, pp. 1565-1572, 2005.

[6] P. E.F. da Silva, E.B. dos Santos and M. de Oliveira, "Vector control for linear induction motor," IEEE International Conference on Industrial Technology, vol. 1, pp. 518-523, 10-12, 2003.

[7] A.K.Rathore and S.N.Mahendra, "Decoupled control of attraction force and propulsion force in linear induction motor drive," IEEE International Conference on Industrial Technology, vol. 1, pp. 524 529, 10-12, 2003.

[8] N. T.Morizane and K.Taniguchi, "Simultaneous control of propulsion and levitation of linear induction motor in a novel maglev system," IEEE Third International Power Electronics and Motion Control Conference PIEMC 2000, vol. 1, pp. 127-131, 15-18, 2000.

[9] L. K.Yosshida and T.Yoshida, "Decoupled-control method of normal and thrust forces in linear induction motor for maglev vehicle marine-express me01," IEEE International Conference IEMD on Electric Machines and Drives, pp. 369-371, 9-12, 1999.

[10] I.Takahashi and Y.Ide, "Decoupling control of thrust and attractive force of a lim using a space vector control inverter," IEEE Transactions on Industry Appl., vol. 29, pp. 161-167, 1993.

[11] T. K.Yoshida and K.Noda, "Influence of instantaneous end effects on attractive levitation force at standstill of combined-levitation-and propulsion slim," IEEE Sixth International Conference on Electrical Machines and Systems, vol. 1, pp. 187-190, 9-11, 2003.

[12] S.Yamamura, Theory of Linear Induction Motors, Tokyo, Japan: University of Tokyo Press, 1972.

[13] J.F.Gieras, Linear Induction Drives. New York: Oxford University Press Inc., 1994.

[14] G. J.F.Gieras and A.R.Eastham, "Performance calculation for singlesided linear induction motors with a double-layer reaction rail under constant current excitation," IEEE Transactions on Magnetics, vol. 22, pp. 54-62, January 1986.

[15] I.Boldea and S.A.Nasar, Linear Motion Electromagnetic Systems. New York: John Wiley \& sons Inc., 1985.

[16] I.Boldea and S.A.Nasar, "A complete equivalent circuit of a linear induction motor with sheet secondary," IEEE Transactions on Magnetics, vol. 24, pp. 639-654, January 1988.

[17] F.Sahin and J.Compter, "Linear induction motor design overview," Tech. Rep. CTB534-05-2574, Philips Applied Technologies, Eindhoven, The Netherlands, 2005.

[18] A.J.D.Verdel, "Decoupled control of thrust and normal forces of linear induction motor for novel magnetically levitated system," Master's thesis, Eindhoven University of Technology, January 2007. 